\title{
Cidades, cultura e gênero ${ }^{1}$
}

Heloisa Pontes

De uma cidade, diz Italo Calvino, aproveitamos menos as suas sete ou setenta e sete maravilhas e mais "a resposta que ela dá às nossas perguntas" (Calvino, 1990, p. 42). A minha, neste ensaio, deriva das relações entre cidade, produção cultural e gênero (entendido como relações sociais e modalidades expressivas de linguagem). Por serem múltiplas as possibilidades de pensá-las, sigo aqui uma trilha que se inicia com um exemplo: os afrescos da capela Brancacci ${ }^{2}$, pintados em Florença, por encomenda de Felipe Brancacci.

Homem ilustre da cidade, que enriquecera com o comércio da seda, Felipe contratou, em 1423, os pintores Masaccio e Masolino para retratarem as cenas mais importantes da vida de São Pedro. A definição do tema, o tipo de contrato que envolveu a encomenda, a escolha dos pintores, a maneira de dar forma aos assuntos bíblicos, tudo isso que já foi tão bem analisado por Baxandall (1988) está presente na história e na realização desse empreendimento, cuja finalidade, assim como a de toda a arte do período, era instruir, suscitar sentimentos de devoção e induzir os fiéis a meditarem sobre a Bíblia e, no caso desses afrescos, a vida de São Pedro.

1. Este ensaio foi apresentado originalmente sob a forma de uma "prova didática", em 10 de dezembro de 2014, em concurso para professor titular - Departamento de Antropologia Social da Universidade Estadual de Campinas, na área de "produção simbólica" - com o objetivo de mostrar as marcas da literatura mobilizada ao longo da aula, na construção dos meus objetos de estudo e trabalho autoral.

2. Meus comentários sobre a capela Brancacci, motivados por uma visita a Florença em 2014, apoiam-se na tradução francesa do texto de Elisa Del Carlo (2012). 
Neles se mesclam fragmentos da realidade social e cultural de Florença ao tempo mítico e bíblico. Vemos cenas da cidade renascentista, marcada pela distância entre a elite e o povo. Reconhecemos ruas e palácios, pessoas com roupas da época, como os dois homens da elite retratados com seus trajes sofisticados e o mazzochi (espécie de turbante) na cabeça, caminhando num cenário tipicamente florentino. Ao lado de personagens e episódios bíblicos, encontramos membros da família Brancacci, chanceleres, um grande senhor de Milão e feroz inimigo da República de Florença, poetas renomados, os três pintores que executaram os afrescos e o mestre de um deles, Sandro Botticelli.

A relação entre a cidade e a sociedade é central para a compreensão desses afrescos. De um lado, porque as convenções pictóricas são produtos culturais que deram corpo, cor e forma às convenções narrativas e religiosas no ambiente social adensado pela vida urbana e pelo mecenato das elites florentinas. De outro lado, porque os contratos, como testemunhos, segundo Baxandall (Idem), das relações sociais entre aqueles que encomendavam e pagavam pelas pinturas e os pintores que as executavam, dão a ver aquilo que o historiador Fernand Braudel nomeou como o "alfa e o ômega" do ofício artístico (Braudel, 1994).

As considerações de Braudel e de Baxandall sobre as relações entre arte, vida urbana e sociedade se desdobram em uma série de problemas epistemológicos e metodológicos. Um deles, relativo à materialidade do objeto cultural sob nosso escrutínio. No caso das obras pintadas há mais de cinco séculos - como os afrescos da capela Brancacci -, que continuam vivas e "presentes entre nós" (Salgueiro, 2006, p. 10), elas, por sua condição a um só tempo visual e material, tendem a criar uma relação de falsa familiaridade produzindo, nos termos de Bourdieu (1992, p. 434), a "semicompreensão ilusória", que "impede-nos de perceber toda a distância entre os esquemas de percepção e apreciação" que lhes aplicamos e o que elas exigem objetivamente para serem decifradas como documento de uma experiência visual e social diversa da nossa. Para escapar dessa armadilha, ensina-nos Baxandall (1988, pp. 153-154), devemos aprender "a ler" um quadro da mesma maneira como devemos adquirir a competência linguística necessária para interpretar um texto proveniente de outra cultura.

Embora toda pintura seja em princípio descritiva, uma vez que ela é arte do espaço e não do tempo, na estética renascentista, mostra-nos Svetlana Alpers (1983, p. xxi), as habilidades imitativas serviam antes de tudo a fins narrativos. A pintura italiana na época em que os afrescos da capela Brancacci foram executados concedia uma primazia à história, usada para comover a alma do observador. Nela, a descrição ocupa um lugar secundário e a ênfase é posta na ação. E isso se exprime simbolicamente pelo uso da perspectiva, que faz do homem o modelo e a medida de todas as coisas. 
Heloisa Pontes

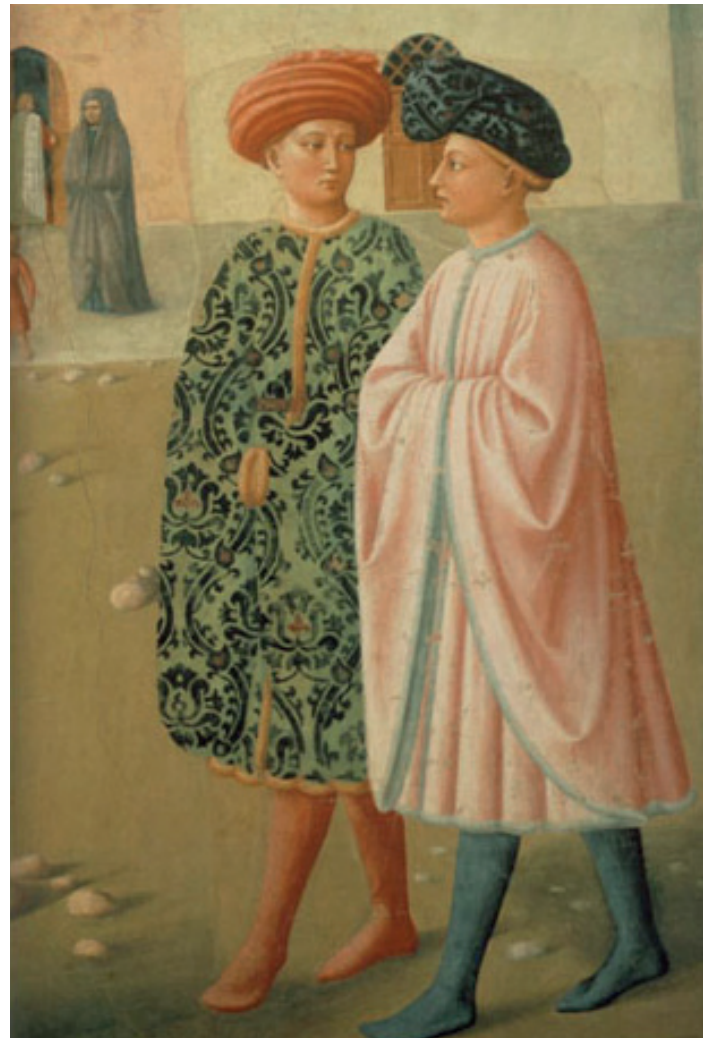

Figura 1. Dois homens da elite de Florença portando na cabeça o mazzochi, em meio a um dos ciclos da vida de São Pedro pintados na capela Brancacci.

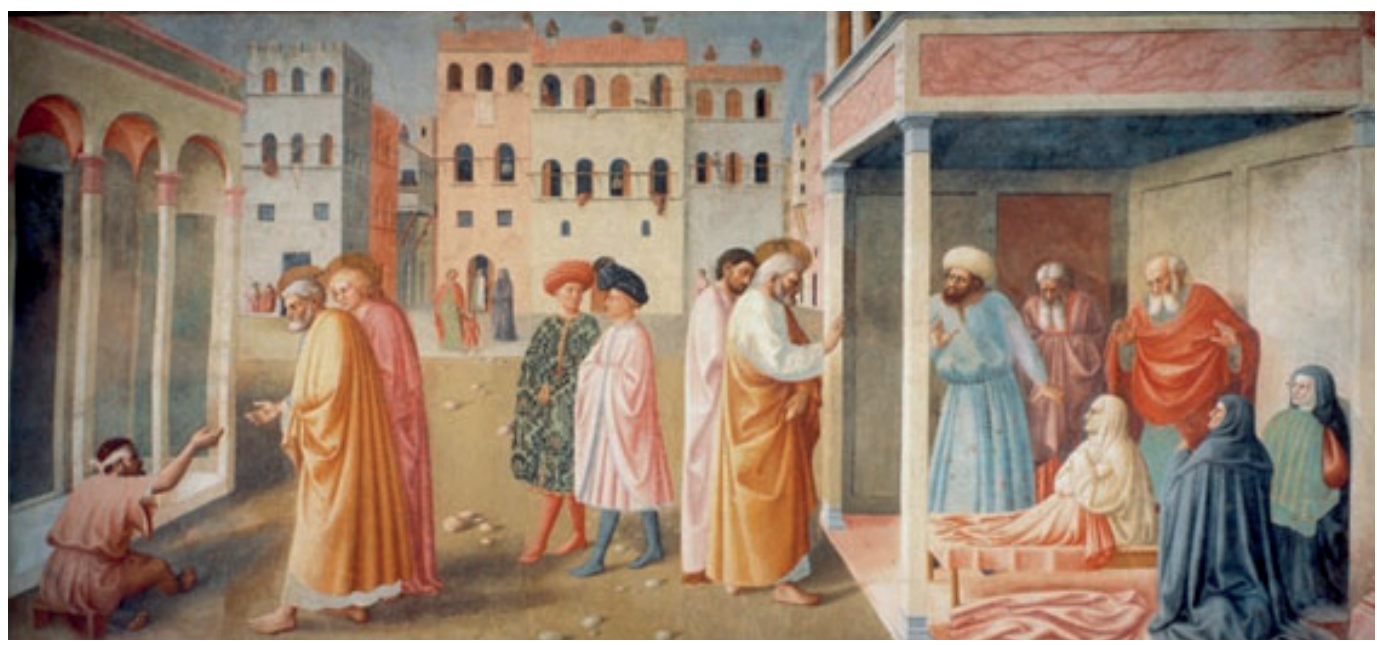

Figura 2. Os dois homens da elite de Florença tal como retratados nos afrescos A cura do enfermo e A ressurreição de Tabita, pintados por Masolino. 


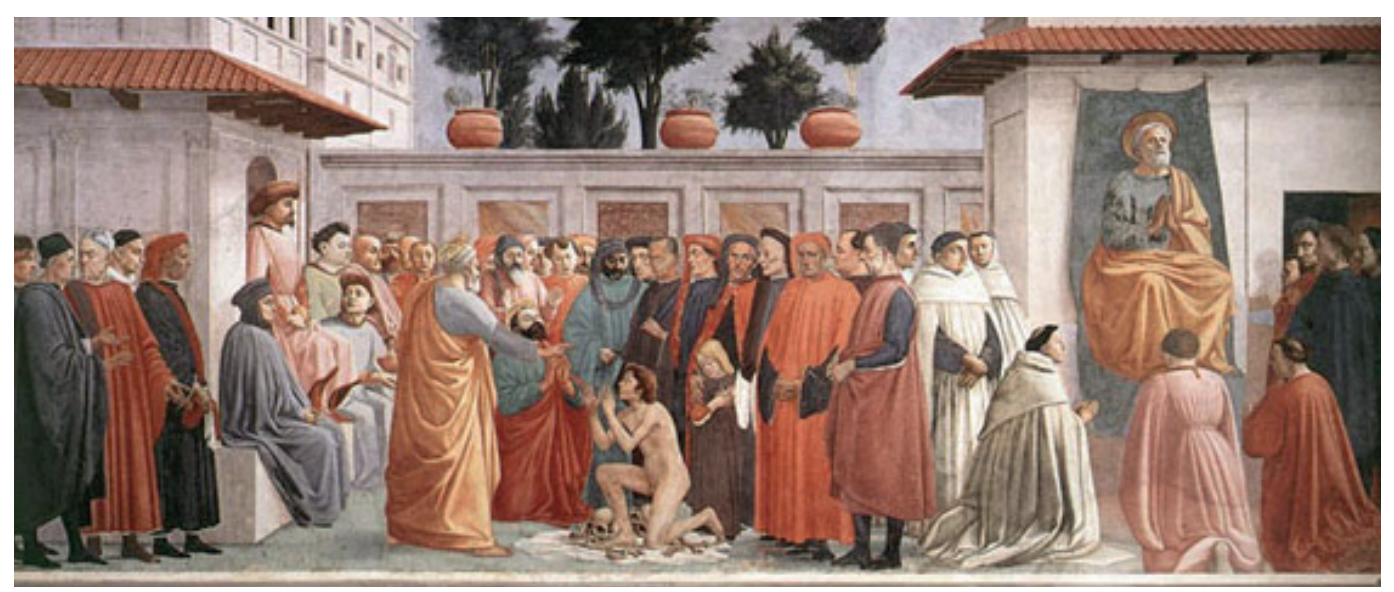

Figura 3. Nesse afresco vemos, em meio à cena bíblica, personagens pintados com os traços de figuras eminentes da época, como Galeazzo Visconti, senhor de Milão e feroz inimigo de Florença, Coluccio Salutati, chanceler da República de Florença, e o próprio pintor do afresco, Masaccio.

Por isso, se, no caso da pintura italiana do "quatrocento", o desafio é nos familiarizarmos com ela e com o mundo social e cultural diverso do nosso, em que ela ganha sentido, o desafio em relação às artes que fazem da descrição e do "deleite dos olhos" a sua razão de ser, como a holandesa, é estranhá-las, para entendê-las. Como nos ensina Svetlana Alpers, as imagens da pintura holandesa do século XVII não dissimulam, tampouco ocultam o sentido por baixo da superfície. Ao contrário, elas mostram que o sentido está contido naquilo que o olho capta. Sendo assim, pergunta-se Alpers, como devemos olhar a arte holandesa desse período? Sua resposta é que devemos olhá-la circunstancialmente, de forma a vê-la para além de uma manifestação social e, assim, acessar as imagens mediante a consideração de seu lugar, papel e presença na cultura mais ampla. Elas são parte de uma cultura especificamente visual, em contraste, por exemplo, com a cultura teatral da Inglaterra no período elisabetano, ou com a cultura textual da renascença italiana (Idem, pp. xxiv-xxv).

Essa maneira de abordar todo e qualquer objeto simbólico a partir de sua inscrição e localização em um sistema de relações modeladas por uma cultura mais ampla é essencial para os que, como eu, praticam a antropologia como uma ciência das formas, dos fundamentos sociais do simbolismo e das dimensões simbólicas da vida social. Por isso, e para avançar na compreensão da produção cultural, é preciso examinar também as condições sociais e os constrangimentos que enredam a criação, os grupos, os gêneros expressivos utilizados. Um exemplo notável nessa direção é a análise de Auerbach sobre a dramaturgia francesa no século XVII, apreendida como uma forma condensada de reprocessamento simbólico de uma experiência social (Auerbach, 1976, pp. 321-352). 
Na estética clássica que impregna a dramaturgia da época, os temas e as maneiras de tratá-los eram divididos em três categorias rigidamente demarcadas: o trágico, grandioso e sublime; o médio, agradável e suave; o ridículo, o baixo e o grotesco (Auerbach, 2007a, p. 309). No gênero considerado mais elevado, da tragédia, cujos representantes máximos eram Corneille (1606-1684) e Racine (1639-1699), "as personagens trágicas, sempre em primeiro plano, assumem uma atitude sublime, rodeada pelos apetrechos, pelo séquito, pelo povo, pela paisagem e pelo universo" (Auerbach, 1976, p. 334). A consciência do Estado principesco é refundida na própria substância da personagem trágica. A condição de príncipe da personagem é muito mais uma atitude do que uma função prática. Sobre o povo fala-se raramente e por meio de expressões gerais. Nenhuma referência às funções corporais, ao dia a dia, ao comer, dormir, beber, a tudo que possa conspurcar o sublime. O corpóreo e a sexualidade, considerados baixos e impróprios, estavam excluídos da paixão trágica.

Nenhum índice físico da fragilidade e da mortalidade da criatura humana deveria ser mostrado no teatro trágico, apenas na comédia e dentro dos limites da decência. Em nenhuma hipótese um herói trágico poderia aparecer fisicamente debilitado. Ninguém podia ser velho, doente, frágil ou deformado. A separação dos estilos atingiu o ponto máximo nesse tipo de dramaturgia. $\mathrm{O}$ distanciamento dos fundamentos econômicos, um ideal de universalidade, hostil a todas as ocupações específicas, está presente também nas comédias de Molière (1622-1673). Nas ricas famílias burguesas de suas peças, a atividade econômica e o ganha-pão são vistos como algo abjeto, sobre os quais não se deve falar (cf. Auerbach, 2007b, pp. 245-264).

Para compreender a dramaturgia desse período é preciso, como faz Auerbach, reinscrevê-la no espaço social que lhe deu sentido, composto pelos dramaturgos, pelo público, pela articulação entre a corte e a cidade, que abrigava a fina camada da burguesia que constituía o público urbano. Sem o entendimento da estrutura social da corte e do absolutismo, da circulação de constrangimentos que enredavam o rei, a nobreza antiga e a nobreza de extração recente (composta pelos burgueses que ascendiam a posições importantes na política e na burocracia pela compra de cargos e de títulos de nobreza, pelo casamento, por decreto real e por usurpação direta), o alcance da nossa compreensão sobre a dramaturgia da época e suas convençóes torna-se muito limitado ${ }^{3}$.

Entrelaçadas, la cour et la ville compunham uma unidade cultural, da qual o povo estava radicalmente excluído. Restrito de início a esse círculo, o teatro se converteria, dois séculos depois, no principal entretenimento nas grandes cidades europeias. Como mostra o historiador Christophe Charle, as peças de sucesso no século XIX

3. Para uma análise aprofundada da estrutura social da sociedade de corte, ver Norbert Elias (1974). 
difundiram novas representações sociais muito antes e muito além das camadas que tinham acesso à literatura. Romances com tiragens expressivas só apareceram no final do século XIX. Já as peças representadas mais de cem vezes para grandes plateias eram frequentes desde os anos de 1850 (Charle, 2012; Pontes, 2012, pp. 9-18).

Eloquentes na difusão de uma sociedade plenamente burguesa, as peças do bulevar parisiense ofereciam ao público que frequentava o teatro em Paris (e nas demais capitais europeias) mais do que a reafirmação de clichês morais envelhecidos. Como revela Charle, mesmo que a maioria das peças não questionasse a legitimidade dos dominantes, elas funcionavam como "caixas de ressonância de descontentamentos indizíveis”. A encenação de conflitos de geração entre pais e filhos (em torno do casamento, da herança, da carreira escolhida), entre grupos e segmentos de classe produzia algo como um "jogo de liberação simbólica”. "O povo, as mulheres, os jovens, eternos dominados pelas convenções dramáticas anteriores, cada vez mais levavam a melhor e invadiam a cena com suas diversas reivindicações." (Charle, 2012, p. 254.)

Ainda que enquadradas e limitadas pelas convenções vigentes na sociedade burguesa, essas novas maneiras de representar as relações sociais tinham implicações importantes no imaginário dos espectadores. Tanto pelo que explicitavam como pelo que silenciavam sobre as transformações sociais e simbólicas da sociedade urbana. Novos modos de conceber as relações entre homens e mulheres e, por extensão, as relações conjugais aparecem em cena, propiciando "diálogos públicos" que, em geral, eram "reprimidos na esfera privada ou mascarados pelas aparências da vida social" (Idem, p. 232). Essas novas formas de representar as relações de gênero permitiam às atrizes, com o recurso das réplicas cortantes que os autores lhes forneciam, afirmarem-se também fora dele. Projetando-se publicamente numa escala até então desconhecida para as mulheres, muitas se tornaram celebridades, como a francesa Sarah Bernhardt (1844-1923) - o exemplo mais notório da influência e do status desfrutado pelas atrizes na época.

Se Paris sediava o epicentro dramático, sua difusão para além da "cidade das luzes" revelava usos e significados inesperados nas demais capitais europeias. Em Viena, como mostra Schorske, o teatro era o centro da "educação sentimental" burguesa. E mesmo quando remodelado na esteira das reformas urbanas promovidas pelos liberais, ele se vinculava, como dramaturgia e espaço de exibição mundana, à tradição aristocrática da "graça" (Schorske, 1998). Enquanto a universidade se afirmava como o lugar por excelência da cultura liberal, assentada na lei e na racionalidade burguesa, o teatro não perdia os vínculos com a cultura plástica e sensual herdada da contrarreforma e da aristocracia.

Talvez, por isso, exista uma ligação tão estreita entre a Viena que se tornou o palco da cultura moderna - a-histórica, ligada à expressão dos sentimentos, aos domínios 
obscuros do erotismo e do inconsciente, em revolta aberta contra o legado racionalista - e as proposições estéticas, as convenções formais e o conteúdo substantivo das artes gestadas na cidade. Artes estas que, conforme demonstrado por Schorske, são inseparáveis da experiência social da elite que as produziu (cf. Schorske, 1993).

Também não é aleatório que a experiência urbana das grandes cidades europeias do século XIX tenha propiciado uma alteração radical na percepção do tempo e do espaço. Como mostrou Simmel, “o fundamento psicológico sobre o qual se eleva o tipo de individualidade da cidade grande é marcado pela intensificação da vida nervosa, que resulta da mudança rápida e ininterrupta de impressões interiores e exteriores" (Simmel, [1903] 2005, pp. 577-591). Essa intensificação do tempo e do deslocamento, que Simmel teorizou em seus ensaios, aparece também em um sonho intrigante, relatado por Leopoldo Waizbort (2000, p. 309), em que Simmel descobre como sintetizar o tempo. No sonho, Simmel se dirige ao metrô e vê o trem partindo, antes que ele pudesse alcançá-lo. Para remedir o atraso, ele risca um palito de tempo e ganha, assim, o minuto a mais que precisava para entrar no veículo.

O sonho do "tempo sintetizado" - imagem invertida da experiência do flâneur - nos conduz ao ensaio de Benjamin e aos exploradores da cidade moderna - como Baudelaire e o anônimo "homem da multidão", imortalizado no conto célebre de Edgar Allan Poe. Célebres ou anônimos, é preciso notar que são todos homens e que alguns, entre eles, foram apresentados à cidade moderna por suas babás, como Benjamin e Freud ${ }^{4}$. Daí "a convergência entre os projetos da psicanálise e do modernismo", segundo Anne McClintock (2010, pp. 132-133). Como mostra a historiadora, "foram as babás que os apresentaram, quando crianças, aos choques e visões do espaço urbano". Mas, antes da cidade, o primeiro espaço que exploraram foi o corpo delas. Assim se "o corpo das babás foi o primeiro espaço para o conhecimento e o autoconhecimento da criança, mais tarde a cidade, como primeiro espaço do autoconhecimento moderno, seria mapeada como um espaço feminino" (Idem).

As narrativas perturbadoras das babás evocadas nas memórias de Zola, Freud e Baudelaire aludem ao poder feminino, à cidade como superfície feminina è à transformação da condição das mulheres em espetáculo. Tal transformação é visível também na dramaturgia, repleta de cortesãs, e mais ou menos dissimuladas, na

4. Agradeço ao Leopoldo Waizbort por me lembrar de que Norbert Elias também experimentou a cidade pelas mãos de sua babá, tal como relatado em Norbert Elias par lui-même, 1991. Na resenha que escreveu sobre a edição brasileira desse livro, Waizbort também nos lembra de que as narrativas de escritores franceses da época descrevendo como "as crianças brincavam, sob o olhar atento das governantas, nos parques parisienses [se tornaram] um 'tropos”. Elias, por exemplo, brincava não nos Campos Elíseos, mas nos jardins de sua cidade natal, Breslau. "A governanta, símbolo do bem-estar da burguesia, zelava pelo menino, quando não protegido pelo interior burguês e pela presença sempre cheia de amor de mamãe." (Waizbort, 2001). 
pintura, pelas convenções pictóricas da época. Por isso, o escândalo produzido pela exibição em 1865 da tela Olympia, de Manet, o qual teria sido motivado, segundo o historiador da arte T. J. Clarck, pelo fato de que nesta tela os "significantes do sexo estão ali em profusão, no corpo da modelo e nos seus acompanhamentos" (Clarck, 2004, p. 198). Dispostos, no entanto, numa ordem diversa da que era habitual entre os pintores para retratar as prostitutas, as cortesãs e seus corpos, tais signos indicam lugares totalmente distintos dos esperados para as mulheres da mesma extração social da modelo que se deixou retratar por Manet. A dificuldade maior dos críticos diante da Olympia residia, segundo Clarck, no fato de que ela não fazia parte da representação da prostituição tal como autorizada pelos enquadramentos vigentes na pintura - e, acrescentaria, tal como encenada nos palcos na época. Não porque a modelo de Manet não tenha sido pintada como uma prostituta e, sim, por ter sido retratada nessa condição sem subterfúgios, exibindo em sua nudez o signo indelével de sua classe.

Se o quadro de Manet foi mais longe que a grande maioria das peças de teatro encenadas na época, no sentido de romper com a maneira pela qual o "corpo da mulher tinha de ser disposto numa relação precisa e definida com o olho do expectador" (Idem, p. 192), nem por isso se deve perder de vista o espaço cultural comum no qual se inscrevem essas representações - cênicas, pictóricas e sociais. Elas revelam a um só tempo a forma dominante de abordagem do nu praticada pela pintura e a apreensão dissimulada da sexualidade feminina no palco (e fora dele).

Por isso mesmo é que, ao delinear a relação entre cidade, produção cultural e gênero, temos que mobilizar antes de tudo "uma história [e uma antropologia] de mediações". Ou seja, uma história social e uma antropologia das relações voltadas para a apreensão dos condicionantes sociais que dão conta, nas palavras de Sergio Miceli, "do teor ambivalente dos arranjos expressivos e das condições responsáveis pelas continuidades e mudanças" na produção cultural e artística (Miceli, 2004, p. 18). Tanto daquelas que se exprimem com o recurso de cores e formas, quanto das que se valem da linguagem, do corpo dos intérpretes, do trabalho dos diretores, do universo imaginado pelos autores, do encontro e dos desencontros entre a sociedade em cena e a sociedade real do palco.

Se até agora tratei de objetos situados nas cidades europeias que culminam com a experiência da modernidade, passo a seguir a abordar a questão central deste ensaio no cenário de duas cidades latino-americanas: Buenos Aires e São Paulo. A primeira será vista de esguelha, para concentrar o foco na capital paulista. Este deslocamento é acompanhado pela formulação certeira de Braudel de que a "história é uma cena de correlações ao mesmo tempo, das quais na melhor das hipóteses só percebemos algumas" (Braudel, 1994, p. 168). 


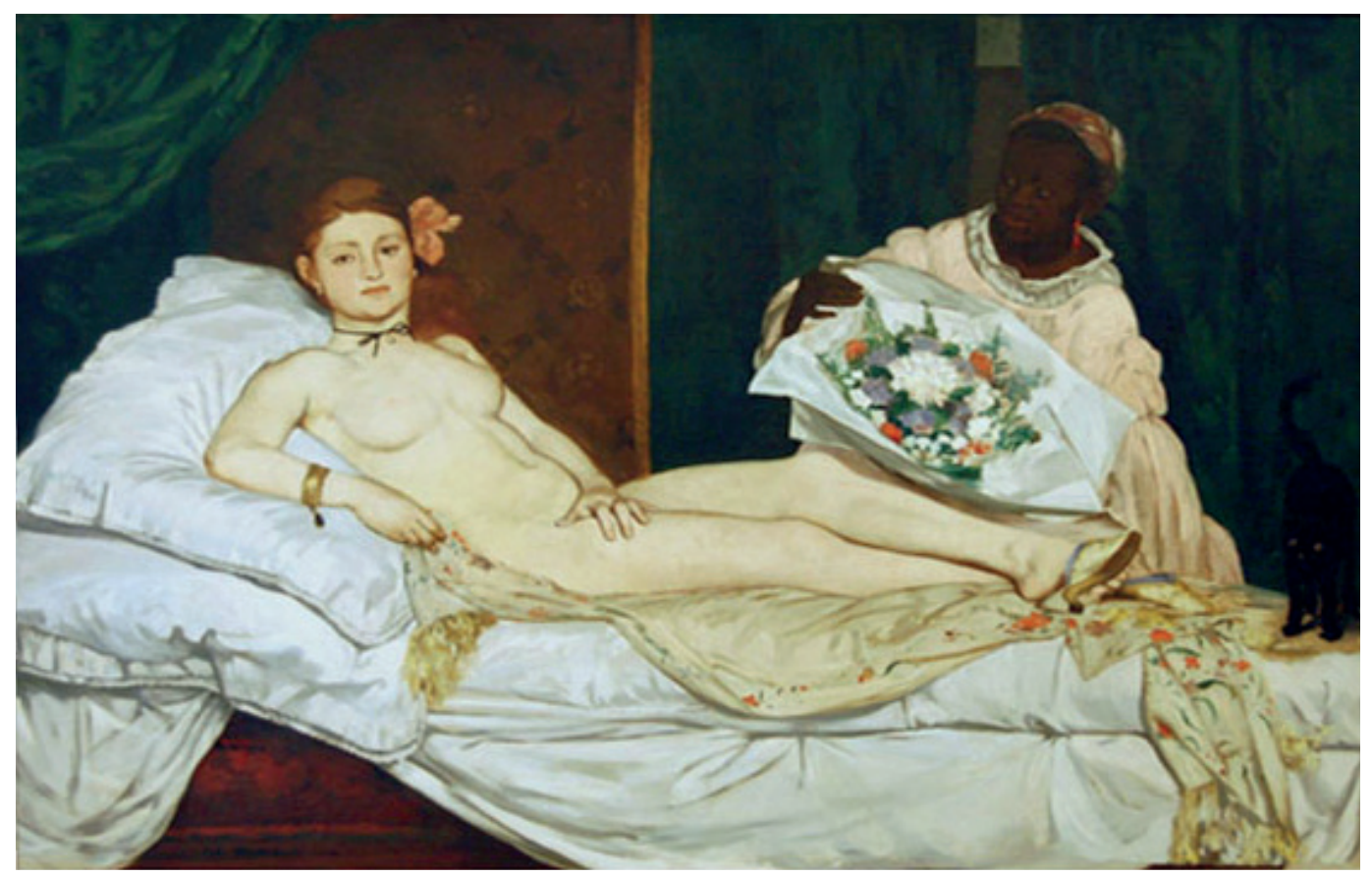

Figura 4. Olympia, de Manet (1865).

Para evitar as explicações apressadas e esquemáticas, adoto o pressuposto de Richard Morse de que nem "a América Latina, nem o modernismo são monolíticos” (Morse, 1995, p. 217). Por essa razão, “a comparação de algumas poucas arenas urbanas pode ajudar a particularizar e a aprofundar nossa compreensão da [tomada de consciência] modernista da década de 1920”. E também de seus desdobramentos no plano da cultura gestada nas metrópoles em expansão. O ponto de partida óbvio, para Morse, é São Paulo, “o centro industrial mais atualizado do continente, uma cidade cujos traços coloniais desapareceram, cujas ruas foram inundadas por italianos, sírios e japoneses, cujo céu foi perfurado da noite para o dia por chaminés" (Idem, ibidem).

A "Paulicéia desvairada", de Mário de Andrade, "a comoção" da vida do papa do modernismo brasileiro, pedia, segundo Morse, "um ato de cognição", e não de "decifração", como o exigido por Buenos Aires. Apesar de diferentes, São Paulo e Buenos Aires têm um ponto inegável em comum: a capacidade de "nos envolver mais com a sensibilidade urbana do que com as questôes nacionais" (Idem, p. 219). A afirmativa de Morse atiça a imaginação sociológica. Quem melhor levou adiante o ato de deciframento em relação à modernidade implantada em Buenos Aires foi Beatriz Sarlo. Por essa razão, o que ela propõe (e alcança), em termos da compreensão do tipo de modernidade gestada na capital argentina, pode ser tomado como uma trilha importante para o estudo da cidade de São Paulo. 
Defensora intransigente da leitura cruzada a partir de múltiplas perspectivas, Beatriz Sarlo sustenta a tese de que se pode falar de muitas maneiras sobre a cultura, a literatura e a arte, "na contramão das disposições de uma polícia epistemológica que opera em nome da estética, do erotismo, do poder da linguagem e de qualquer outra aura moderna ou pós-moderna” (Sarlo, 1998, p. 9). Seu livro sobre a cultura urbana e a modernidade periférica de Buenos Aires mescla história cultural, crítica literária, história intelectual, história dos intelectuais e das ideais. Esta foi a forma e o partido analítico que Beatriz Sarlo tomou para apreender, interpretar e explicar "de que maneira os intelectuais argentinos, nos anos 20 e 30 do século passado, viveram os processos de transformações urbanas e experimentaram um conjunto de sentimentos, ideais, desejos muitas vezes contraditórios, em meio a um espaço moderno como já era o de Buenos Aires na época” (Idem, ibidem).

Em São Paulo, outra analista notável, a socióloga Maria Arminda do Nascimento, movida por desafios similares aos de Beatriz Sarlo, perscrutou as correlações entre o processo acelerado de metropolização da cidade no meio do século xx e suas consequências no plano da cultura. Ao fazer isso, na esteira do legado do livro pioneiro de Morse sobre São Paulo, Maria Arminda oferece uma compreensão renovada do pluralismo cultural da cidade e do complexo entrelaçamento entre modernização, modernismo e modernidade. "Os anos de 1950 [em São Paulo] representam um momento de explosão das diferentes linguagens, um claro sintoma de complexidade do tecido social e de evidente manifestação de enraizamento do Modernismo" (Arruda, 2015, p. 28). A constatação leva a autora a "caracterizar as diversas manifestações do moderno contidas na multiplicidade das linguagens, buscando as relações que entretêm com o movimento profundo de transformação da vida na cidade" (Idem, p. 27).

A aproximação da autora com o problema do tempo específico da cultura urbana de São Paulo se deu pela "via da linguagem, quando [percebeu] a possibilidade de estabelecer um trânsito entre a sociologia e outras formas expressivas, no plano exclusivo da construção dos estilos" (Idem, p. 33). A apreensão desse trânsito em chave sociológica implica um duplo desafio. De um lado, a busca pela especificidade de cada uma das linguagens que se firmaram no período: a dramaturgia de Jorge Andrade, a sociologia de Florestan Fernandes, o concretismo nas artes, a arquitetura do Parque Ibirapuera. De outro lado, a recomposição da totalidade fragmentada que articula essas novas linguagens no mesmo tecido urbano em transformação. $\mathrm{O}$ movimento analítico da autora, inspirado na análise iluminadora de Schorske, permite que ela estabeleça similaridades entre a Viena do final do século xıx e a São Paulo da metade do século Xx. Entre elas, “a mesma recusa do passado”, que repõe, nas duas cidades, “a frustração diante da história”, a “invasão do presente pleno de experiências sociais 
diversas", "a fragmentação das linguagens" em meio aos "contextos atravessados por impasses e dilacerados por tensões" (Idem, p. 50).

Enquanto Richard Morse buscou o ambiente urbano descrito e experimentado pelos agentes, Maria Arminda perseguiu as transformações urbanas pelo prisma das linguagens e das instituições que lhes deram guarida. Na esteira desses autores, meu interesse, ao estudar a cidade de São Paulo, foi analisar os intérpretes dessas novas linguagens. Entre eles, os intelectuais que, no início dos anos de 1940, lançaram a revista Clima e tinham como diferencial o fato de serem oriundos da primeira geração universitária formada na Faculdade de Filosofia, Letras e Ciências da Universidade de São Paulo. Entre os nomes mais expressivos desse círculo, encontram-se Antonio Candido, Paulo Emílio Salles Gomes, Décio de Almeida Prado, Lourival Gomes Machado, Ruy Coelho, Gilda de Mello e Souza5.

Nascidos entre 1916 e 1920, eles se conheceram na faculdade e se uniram pelo resto da vida por fortes laços de amizade e por uma intensa sociabilidade. Juntos lançaram-se na cena cultural paulista por meio de uma modalidade específica de trabalho intelectual: a crítica aplicada ao teatro, ao cinema, à literatura e às artes plásticas. Como produtos do novo sistema de produção intelectual implantado na Faculdade de Filosofia da Universidade de São Paulo, por intermédio dos professores estrangeiros (franceses, em particular), eles renovaram a tradição ensaística brasileira. Como críticos "puros", romperam com a concepção de trabalho e com o padrão de carreira da geração anterior (que tinha um pé na literatura e outro na doutrina política). Como intelectuais, diferenciaram-se dos modernistas e dos cientistas sociais com os quais conviveram na Universidade de São Paulo.

Situados entre os literatos, os modernistas, os jornalistas polígrafos e os cientistas sociais, eles construíram seu espaço de atuação por meio da crítica, exercida em moldes ensaísticos, mas pautada por preocupações e critérios acadêmicos de avaliação. Eles fizeram a "ponte" entre a Faculdade de Filosofia e as instâncias mais amplas de produção e difusão cultural da cidade. Como críticos, inseriram-se na grande imprensa, nos projetos editoriais, nos empreendimentos culturais mais amplos da cidade de São Paulo. Como intelectuais acadêmicos, profissionalizaram-se na Universidade de São Paulo e formularam um dos mais bem-sucedidos projetos de análise da cultura brasileira. O fato de atuarem ao mesmo tempo como críticos de cultura, acadêmicos e professores universitários sinaliza o alcance das transformações que estavam ocorrendo na cidade de São Paulo e em seu sistema cultural ao longo das décadas de 1940 e 1950 . Tais transformações impulsionaram novas maneiras de conceber e praticar o trabalho intelectual.

5. Para uma visão mais aprofundada do grupo e da revista, ver Pontes (1998). 
Outra novidade trazida pelo Grupo Clima era a presença de jovens universitárias entre os integrantes do grupo. Apesar disso, apenas uma delas, Gilda de Mello e Souza (1919-2005), conquistou um “nome próprio”, em razão de sua trajetória acadêmica e dos trabalhos que produziu nas áreas de sociologia e estética. Para avançar a compreensão das relações de gênero no campo intelectual marcadamente masculino da época, é preciso comparar as trajetórias das mulheres que se destacaram. O cotejamento entre Gilda de Mello e Souza, a modernista Patrícia Galvão (19101962) e a crítica de cultura Lúcia Miguel Pereira (1901-1959) permite aquilatar os condicionantes que modelaram os espaços possíveis para a atuação das mulheres na época e os constrangimentos decorrentes das relações de gênero - apreendidas em relação e na relação com outras dimensões igualmente relevantes para a apreensão da estrutura e da dinâmica específica dos campos de produção cultural ${ }^{6}$. Uma trilha vigorosa nessa direção é a comparação com o que ocorria com as mulheres e os homens ligados à cena teatral nesse mesmo período. $\mathrm{O}$ cotejo e a justaposição do campo intelectual à cena teatral da metrópole em expansão permitem ainda ressaltar a urdidura sociológica que os alinhavou sincronicamente em uma mesma trama cultural, entre os anos de 1930 e $1960^{7}$.

No contexto de implantação das rotinas de trabalho e das concepções artísticas do teatro moderno, o crítico Décio de Almeida Prado (1917-2000), ligado ao Grupo Clima, e a atriz Cacilda Becker (1921-1969) foram uns dos maiores responsáveis pelo dinamismo da cena teatral paulista. Conforme Cacilda Becker crescia como atriz $^{8}$, Décio de Almeida Prado firmava-se como a "consciência privilegiada" (Magaldi, 2002, p. Ix) da renovação cênica que teve lugar em São Paulo com os grupos amadores e com o Teatro Brasileiro de Comédia (ТВC), criado em 1948. Símbolo do teatro paulista na virada da década de 1940 e referência obrigatória nos anos de 1950 , о TBC conferiu às atrizes que atuaram na companhia uma projeção excepcional. O prestígio conquistado por elas e pelos atores com os quais contracenaram deve-se à transferência da autoridade social e cultural do público de extração burguesa que frequentava o teatro. Deve-se também à participação que os intérpretes tiveram no movimento de implantação e sedimentação dos princípios estéticos e das rotinas de trabalho do teatro moderno.

Pelo твC passaram algumas das maiores atrizes brasileiras (Fernanda Montenegro, Cacilda Becker, Tônia Carrero, Nydia Lícia, Cleyde Yáconis e Maria Della Costa). O renome conquistado por essas atrizes é inseparável de suas parcerias amorosas e

6. Para um desenvolvimento deste argumento, ver Pontes (2008).

7. Para um aprofundamento da comparação entre esses dois campos de produção simbólica, ver Pontes (2010).

8. Sobre a importância da atriz no teatro paulista da época, ver Pontes (2004). 
de trabalho. Com essa afirmação não pretendo diminuir o brilho e o talento dessas intérpretes, tampouco minimizar a dedicação com que elas construíram suas carreiras. Essas atrizes viveram uma situação inversa à das mulheres intelectuais na época, que enfrentaram uma série de constrangimentos para se afirmarem e "fazer nome". Entre eles, a conciliação da carreira com a família, ou, quando casadas com intelectuais de renome, os conflitos advindos de se sentirem ou serem vistas à "sombra” dos maridos. Já as atrizes foram alçadas à condição de protagonistas com a anuência e o respaldo dos parceiros. Seguindo a tradição no meio teatral do autoempresariamento, elas criaram suas companhias, nas quais figuraram como principal chamariz. Enquanto isso seus parceiros atuaram como diretores, intérpretes, empresários, mesclando às vezes as três atividades. É preciso frisar, no entanto, que as razões para o empenho diverso desses parceiros, maridos ou amantes não consistem em disposições pessoais isoladas, explicáveis por “temperamento" ou "boa-vontade”. Residem antes nas dinâmicas particulares dos campos de produção simbólica, mais ou menos refratários às inflexões de gênero e à atuação das mulheres?

Pela mescla de condições objetivas e subjetivas, o contexto era propício para as atrizes, para os atores, para aqueles que sonhavam em fazer da dramaturgia uma profissão. Entre as condições objetivas, sobressaem os novos espaços de sociabilidade e de profissionalização que se abriam em São Paulo e as alterações que se produziam em passo acelerado na estrutura social e demográfica da cidade. Em menos de três décadas, a população de São Paulo quintuplicara, passando dos 579 mil, cifra registrada em 1920, para 2 milhões e 198 mil habitantes na década de 1950. A cidade, "explodindo em número de habitantes, quebrava a sua velha carapaça quatrocentona, internacionalizando-se”, nas palavras de Décio de Almeida Prado (1998, p. 7). A consequência disso era a crença partilhada no futuro, "a substituição simétrica de estilos de vida e não o lento desaparecimento de um mundo cuja agonia se pudesse acompanhar com lucidez" (Mello e Souza, 1980, p. 110), como dá a ver a dramaturgia de maior inventividade encenada nas décadas de 1950 e 1960.

Arte social, arte coletiva, arte da representação, inseparável da vida urbana e da sociabilidade multifacetada, o teatro em São Paulo converteu-se em laboratório voluntário e compulsório dos sonhos acalentados pelas camadas médias e pelas elites. Ele deu forma a assuntos que pulsavam, antecipou comportamentos que se tornaram emblemáticos, forneceu régua e compasso para enquadrar as transformações em curso. Assim, não é aleatório que a sociedade encenada no palco encontrasse tamanha ressonância na sociedade real do público ${ }^{10}$. A dramaturgia de Jorge Andrade (1922-

9. Desenvolvo esse argumento no sexto capítulo do meu livro Intérpretes da metrópole, 2010.

10. Para o aprofundamento desse pressuposto, enfeixado pela relação entre cidade, teatro, público e socie- 
1980) e Gianfrancesco Guarnieri (1934-2006), para citar dois dos autores mais inventivos do período, sintetizou as representações inquietantes de uma sociedade em fogo morto, sobre a qual sobrevinha a lufada de energias impulsionadas pelos grupos emergentes. Enquanto Jorge Andrade remexeu as feridas dos abastados de ontem ${ }^{11}$, Guarnieri fabricou uma classe operária povoada pelo ideário dos setores médios em ascensão $^{12}$. A derrocada da economia cafeeira engolfou proprietários, linhagens, estilos de vida, critérios de prestígio, valores e certezas. A expansão da metrópole espicaçou a imaginação social, criou linguagens, produziu novos enfrentamentos e utopias. A cena teatral paulista na década de 1950, antenada com as transformações em curso, abrigou o adeus à civilização do café e a exaltação da sociedade urbano-industrial. Nos palcos da cidade, ganharam tratamento renovado as vicissitudes dos setores médios, o impacto da vida urbana nos costumes e nas relações familiares, a experiência da classe operária, a ascensão dos imigrantes, cuja presença em sucessivas levas migratórias conformou a paisagem social e urbana da metrópole em expansão ${ }^{13}$.

Na década de 1960, a criação de novos grupos, a consolidação do Teatro Oficina e do Teatro de Arena, a expansão do público jovem, universitário e de esquerda, a sedimentação do "conceito de engajamento artístico de esquerda" (Napolitano, 2001), a estreia de novos dramaturgos, tudo isso, somado, alterou a composição social do palco. A combinação entre "a cena 'rebaixada' e um público ativista” (Schwarz, 1978, p. 81), aliada à introdução de novas temáticas e de novas maneiras

dade, ver Auerbach (2007b), Schorske (1998) e Charle (2008; 2012).

11. Na peça $A$ moratória (encenada em 1955), a lembrança objetivada do descenso social da família de Jorge Andrade impregna tanto a fala dos personagens como os objetos que os cercam. Antes de tudo, as casas que habitam: a do passado, da opulência e do mando; a do presente, modesta e sem brilho. Ela também se condensa no relógio pendurado na sala de jantar; nos santos nas paredes; na máquina de costura, que serviu de recreio à menina rica do passado e de esteio da família no descenso do presente. Atando significados simbólicos e relações sociais, a casa e os objetos nas peças de Jorge Andrade são mais que peças de cenário. Neles se inscreve a história social da família, que é também a da classe a que pertenceu o dramaturgo - a oligarquia agrária ligada ao café.

12. Na peça Eles não usam black-tie, de Guarnieri (encenada em 1958), o título alude à indumentária de gala dos espectadores que frequentavam a companhia de maior projeção no período, o paulistano Teatro Brasileiro de Comédia. No traje de festa sobressaíam as insígnias vistosas da ostentação burguesa, rechaçada pelo público jovem, levemente desalinhado e afinado com o polo mais à esquerda do campo teatral. Sucesso estrondoso, a peça ficou um ano em cartaz, garantiu uma sobrevida inesperada ao Teatro de Arena, alimentou os sonhos de uma geração sobre o potencial da cultura na transformação e reordenação das relações sociais. Por seu intermédio, a classe operária entrou pela primeira vez nos palcos da metrópole, na pegada forte do drama de uma família tensionada pela greve, pelo conflito de gerações e pela luta de classes. Para dar verossimilhança à experiência social de uma classe que não era a sua, Guarnieri mesclou o imaginário de sua geração, alimentado pela militância política no Partido Comunista, à memória por procuração.

13. Para um aprofundamento da análise das peças em tela de Jorge Andrade e Gianfrancesco Guarnieri, ver Pontes e Miceli (2012). 
de dizê-las, teve um efeito extraordinário no palco e um acolhimento vibrante do público engajado. O teatro ecoava e a um só tempo vocalizava, nas palavras de Roberto Schwarz, a “relativa hegemonia cultural da esquerda”. Ele era um dos termômetros a medir a alta temperatura cultural do país, que "estava irreconhecivelmente inteligente" (Idem, p. 69), apesar da ditadura militar instaurada em 1964. Quatro anos mais tarde - após a decretação do Ato Institucional n. 5 (AI5), em dezembro de 1968, pela junta militar que comandava o país -, as forças repressivas e conservadoras, impulsionadas pela censura, pela ampliação das perseguições políticas e pela suspensão da liberdade de imprensa, não mediram esforços para desmontar a hegemonia cultural da esquerda e liquidar o sonho da revolução acalentado por uma parcela expressiva da juventude engajada.

O teatro acompanhou de perto a ferocidade desse desmonte, virou um reduto da resistência - comprovando a tese de Schorske de que a dramaturgia é "a forma literária mais adequada à esfera da ação e, portanto, à ética e à política” (1993, p. 40) - e sempre que possível contornou a censura com o recurso da burla e da linguagem cifrada. Os censores não davam trégua e os dramaturgos faziam das tripas coração para manter um controle mínimo sobre o que escreviam. E ainda que a censura tenha sido inclemente, impedindo a montagem das peças ou retirando outras de cena, ela deixou passar assuntos, temas e maneiras inusitadas de abordá-los. Ao que tudo indica por incapacidade e cegueira para perceber a novidade em curso, como as trazidas por Mariazinha e Verônica e pelo universo social que confirmou a existência de ambas ${ }^{14}$.

Essas duas personagens foram vistas juntas, quase lado a lado, nos palcos da metrópole paulista pelo público jovem que continuou a buscar refrega na cultura. Jovens, inquietas e destemidas eram também as dramaturgas que as criaram: Leilah Assumpção (1943) e Consuelo de Castro (1946). As duas dramaturgas fizeram valer os trunfos da formação sofisticada recebida na Universidade de São Paulo para driblar as vicissitudes de uma cena cultural ainda hostil e reticente às pretensões de dicção e criação autoral das mulheres. $\mathrm{O}$ aprendizado misturado à sociabilidade praticada por inteiro no centro de irradiação da universidade garantiu às jovens estreantes na dramaturgia a ousadia necessária para assumirem riscos na escrita (e na vida). As peças de estreia que as tornaram conhecidas, calibradas pelo viés das marcas de classe e de gênero, desarrumaram as convenções dramáticas usuais. Em pleno regime militar, elas miraram as experiências desconcertantes das protagonistas femininas e os impasses de toda ordem que as condensavam - materiais, profissionais, sexuais,

14. Para um desenvolvimento da análise dessas personagens, das peças e das dramaturgas que as criaram, ver Pontes (2014). 
éticos. Mas no lugar de encapsularem as personagens no quadro estreito da chamada condição das mulheres, elas encenaram relações de gênero. Materializadas nos objetos, no par amoroso, nos estilos de feminilidade e masculinidade, as relações de gênero foram corporificadas também pelas personagens masculinas. Os homens, nessas peças, atiçavam a libido, solapavam as balizas correntes do relacionamento amoroso e escancaravam os limites de todos no mundo social em transformação convulsa retratado nos palcos.

Nas peças com que estrearam como dramaturgas, Fala baixo senáo eu grito e $\dot{A}$ flor da pele (encenadas em 1969), Leilah Assumpção e Consuelo de Castro arriscaram inovações substantivas em diversas frentes e dimensões. Constituíram as protagonistas femininas em sujeito da ação, o retrovisor das projeções do espectador, o móvel dos dilemas éticos. Fizeram com que a temática feminina invadisse o cerne da trama e se convertesse em filtro privilegiado das mudanças sociais em curso. Mudanças que estavam prensadas entre o desgaste dos modelos tradicionais de classe e de gênero, o influxo de energias represadas, o acerto de contas com as utopias e os desacertos políticos do passado recente. A dramaturgia dessas autoras deslocou a urgência da transformação para o plano das relações amorosas, menos sujeitas às investidas crescentes da ditadura e da censura. Assim como as novas carreiras universitárias nas humanidades impulsionaram "vocações” de moças talentosas, os palcos da metrópole paulista ecoaram experiências de vida até então descartadas pelo crivo da modelagem simbólica em mídias e suportes destinados a um público mais amplo e diversificado. Nesse contexto, o teatro forneceu régua e compasso para o desenho de novos sujeitos e novos regimes de enunciação.

Ato final

Partilhando o pressuposto de Adorno, "a forma como um conteúdo social sedimentado”, procurei enquadrar o assunto central deste ensaio - configurado pelas diversas possibilidades de apreender as relações entre cidade, produção cultural e gênero - a partir do rastreamento da dramaturgia de maior fôlego e inventividade encenada nos palcos da metrópole paulista. Argumentei que ela funcionou como uma caixa de ressonância das transformações que estavam ocorrendo em ritmo acelerado na cidade de São Paulo e, ao mesmo tempo, como agente de produção dessas mudanças. Essa dramaturgia pode (e deve) ser apreendida como a transcrição do gosto, dos valores, da visão de mundo dos artistas e intelectuais que apostaram as fichas na cultura, como meio privilegiado de transformação das relações sociais. Em uma situação bem diversa dos pintores florentinos encarregados do ciclo de afrescos da capela Brancacci, mencionados no início do ensaio, os dramaturgos e as 
dramaturgas em São Paulo partilhavam a crença no potencial libertador da cultura. Não porque fossem melhores que os pintores florentinos, Masolino, Masaccio e Filippino Lippi, mas porque as cidades em que se inseriram mantinham relações distintas com a cultura.

O exemplo da capela Brancacci mostra a importância de determinadas manifestações artísticas para a compreensão das cidades que as abrigam. Na Florença do século XV, a pintura era uma das artes de maior prestígio e visibilidade da cidade. Em São Paulo da metade do século xx, o teatro ocupou essa posição em função da centralidade que ele adquiriu na vida cultural da cidade.

Em Florença, no período em que os afrescos da capela Brancacci foram pintados, a arte e o pensamento, como mostrou Braudel, "se orientavam e se decidiam no alto das hierarquias sociais. O resto da população, o 'popolo', estava fora do jogo" (Braudel, 1994, p. 58). Era a parte alta da sociedade florentina restrita que dava o tom e o tônus da produção cultural na cidade. A Florença daquela época abrigava "uma sociedade fraturada em duas: o pequeno grupo que participava da cultura refinada e a massa” (Idem, pp. 57-58), reduzida à condição obscura de espectadora. A "civilização desabrochava no alto da sociedade como um mergulhador que volta à superfície”, para completar o argumento com a frase iluminadora do historiador francês (Braudel, 1994, p. 39). Na São Paulo de meados do século xx, a produção cultural enfeixada nas novas linguagens, que se expressavam na arquitetura, nas artes plásticas, na sociologia e na dramaturgia, revelava uma relação ampliada com a cidade. Ainda que essa produção cultural estivesse longe de atingir as massas, apesar da aposta política de vários artistas e intelectuais de maior vitalidade, ocorreu inegavelmente uma ampliação das bases e do acesso à cultura.

A arte, o teatro e a literatura são uma "linguagem para as sociedades que as falam, que as escutam" (Idem, p. 69), que as apreciam em certas conjunturas ou as rechaçam em outras. Por isso, é necessário afinar os conceitos e as ferramentas metodológicas da história, da antropologia e da sociologia para escutá-las. É preciso, ainda, perscrutá-las como documentos transfigurados da imaginação social, especialmente quando inscritas em paisagens urbanas inquietantes e vigorosas como as abordadas neste ensaio, enfeixadas pela formulação precisa de Adrián Gorelik: "as cidades e suas representações se produzem mutuamente” (Gorelik, 2011, p. 138).

\section{Referências Bibliográficas}

Alpers, Svetlana. (1983), The art of describing: Dutch Art in the Seventeenth Century. Chicago, University of Chicago Press. 
Andrade, Jorge. (1986), Marta, a árvore e o relógio. 2. ed. ampl. São Paulo, Perspectiva.

Arruda, Maria Arminda do Nascimento. (2015), Metrópole e cultura: São Paulo no meio século $X X$. São Paulo, Edusp.

AssumpÇão, Leilah. (2010), Fala baixo senão eu grito. In: . Onze peças de Leilah Assump̧̧ão. Rio de Janeiro, Casa da Palavra.

Auerbach, Erich. (1976), “O santarrão”. In: . Mimesis: a representação da realidade na literatura ocidental. 2. ed. São Paulo, Perspectiva, pp. 321-352. . (2007a), "As flores do mal e o sublime". In: . Ensaios de literatura ocidental.

Org. Davi Arrigucci Jr. e Samuel Titan. São Paulo, Duas Cidades/Editora 34, pp. 303-332. . (2007b), "La cour et la ville". In: . Ensaios de literatura ocidental. São Paulo, Duas Cidades/Editora 34, pp. 211-278.

BaXandall, Michael. (1988), Painting and experience in Fifteenth Century Italy. 2. ed. Nova York, Oxford University Press.

. (2006), Padrões de intenção: a explicação histórica dos quadros. São Paulo, Companhia das Letras.

Bourdieu, Pierre. (1992), Les règles de l'art: genèse et structure du champ littéraire. Paris, Editions du Seuil (ed. bras.: As regras da arte: gênese e estrutura do campo literário. Trad. Maria Lucia Machado. São Paulo, Companhia das Letras, 1996).

Braudel, Fernand. (1994), Le modèle italien. Paris, Flammarion.

Calvino, Italo. (1990), As cidades invisiveis. São Paulo, Companhia das Letras.

Carvalho, Maria Alice. (1994), Quatro vezes cidade. Rio de Janeiro, 7 Letras.

Castro, Consuelo de. (1989), À flor da pele. In: Urgência e ruptura. São Paulo, Perspectiva/Secretaria de Estado da Cultura. . (2006), Depoimento audiovisual concedido a Daisy Perelmutter e Luis Francisco de Carvalho, no âmbito do projeto "Memória oral da Biblioteca Mário de Andrade".

Charle, Christophe. (2008), Théâtres en capitales. Paris, Albin Michel. . (2012), A gênese da sociedade do espetáculo. São Paulo, Companhia das Letras.

Clarck, T. J. (2004), A pintura da vida moderna: Paris na arte de Manet e de seus seguidores. São Paulo, Companhia das Letras.

Del Carlo, Elisa. (2012), La Chapelle Brancacci. Florença, Mandragora.

Elias, Norbert. (1974), La société de cour. Paris, Calmann-Lévy. . (1991), Norbert Elias par lui-même, Paris, Fayard.

Gorelik, Adrián. (2011), Correspondencias: arquitectura, ciudad, cultura. Buenos Aires, Nabuko.

GUARNIERI, Gianfrancesco. (2001), Eles não usam black-tie. 12. ed. Rio de Janeiro, Civilização Brasileira.

Lanna, Ana Lúcia et al. (orgs.). (2011), São Paulo, os estrangeiros e a construção das cidades. São Paulo, Alameda. 
Magaldi, Sábato. (2002), “Consciência privilegiada do teatro”. In: Prado, Décio de Almeida. Apresentação do teatro moderno brasileiro. São Paulo, Perspectiva, pp. ix-xv.

McClintock, Anne. (2010), Couro imperial: raça, gênero e sexualidade no embate colonial. Campinas, Editora da Unicamp.

Mello e Souza, Gilda. (1980), “Teatro ao sul”. In: . Exercícios de leitura. São Paulo, Duas Cidades, pp. 109-116.

Miceli, Sergio. (2004), "Por uma história social da arte". In: Clark, T. J., A pintura da vida moderna: Paris na arte de Manet e de seus seguidores. São Paulo, Companhia das Letras, pp. 9-18.

Morse, Richard. (1995), “As cidades 'periféricas' como arenas culturais: Rússia, Áustria, América Latina”. Estudos Históricos, 8 (16): 205-225 (originalmente publicado no Journal of Urban History, 1984, 4 [10]).

Napolitano, Marcos. (2001), “A arte engajada e seus públicos, 1955-1968”. Estudos Históricos, 28 (2): 103-124

Pontes, Heloisa. (1998), Destinos mistos. São Paulo, Companhia das Letras. . (2004), "A burla do gênero: Cacilda Becker, a Mary Stuart de Pirassununga”. Tempo Social, 1 (16): 231-262.

. (2008), "Crítica de cultura no feminino". Mana - Estudos de Antropologia Social, 2 (14): 511-541.

. (2010), Intérpretes da metrópole. São Paulo, Edusp/Fapesp.

. (2012), "Introdução à edição brasileira: sociedade em cena". In: CHARLE, Christophe. A gênese da sociedade do espetáculo. São Paulo, Companhia das Letras, pp. 9-18.

. (2014), "Mariazinha e Verônica: classe e gênero nos palcos da metrópole". In:

\& Miceli, Sergio (orgs.). Cultura e sociedade: Brasil e Argentina. São Paulo, Edusp, pp. 187-209.

\& Miceli, Sergio. (2012), "Memória e utopia na cena teatral". Sociologia \& Antropologia, 4 (2): 241-263.

Prado, Décio de Almeida. (1998), “твC - Teatro Brasileiro de Comedia revê os seus 50 anos". O Estado de S. Paulo, caderno 2, p. 7

Ridenti, Marcelo. (2000), Em busca do povo brasileiro. Rio de Janeiro, Record.

SAlgueiro, Helena Angotti. (2006), "Introdução à edição brasileira”. In: BAXANdall, Michael. Padrões de intenção: a explicação histórica dos quadros. São Paulo, Companhia das Letras.

SARlo, Beatriz. (1998), Una modernidad periférica: Buenos Aires, 1920 y 1930. Buenos Aires, Nueva Visión.

Schorske, Carl. (1993), Viena fin-de-siècle. São Paulo, Companhia das Letras. (1998), "Grace and the word: Austria's two cultures and their modern fate". In:

Thinking with history: explorations in the passage to modernism". Princeton, Princeton University Press. 
SCHWARZ, Roberto. (1978), “Cultura e política”. In: . Opai de familia e outros estudos.

Rio de Janeiro, Paz e Terra.

Simmel, Georg. ([1903] 2005), “As grandes cidades e a vida do espírito". Trad. Leopoldo Waizbort. Mana - Estudos de Antropologia Social, 2 (11): 577-591.

Waizbort, Leopoldo. (2000), “Georg Simmel e a Berlim do Segundo Império”. In: As aventuras de Georg Simmel. São Paulo, Editora 34. . (2001), "Monólogos no exílio". Folha de S. Paulo, caderno Mais!, 15 abr.

\section{Resumo}

Cidades, cultura e gênero

Centrado na apreensão das conexões empíricas e das inter-relações analíticas entre produção cultural, cidade e gênero, o artigo visa a um tríplice objetivo: mapear alguns dos modelos teóricos utilizados na análise e interpretação desses fenômenos; discutir uma bibliografia específica sobre cidade, linguagem artística e experiência social; analisar o entrelaçamento dessas dimensões na cidade de São Paulo, nos anos de 1940 a 1960, com foco na dramaturgia e com o auxílio de exemplos retirados de Florença, Paris e Buenos Aires. Entendendo as cidades como arenas culturais, como "lugar de germinação, de experimentos e de combate cultural" (Morse), o artigo partilha a ideia de que "as cidades e suas representações se produzem mutuamente" (Gorelik) e defende o argumento de que determinadas manifestações culturais só acontecem em cidades específicas em função das condições sociais, do potencial e dos constrangimentos que enredam a criação, a autoria, a linguagem e as relações de gênero.

Palavras-chave: Cidade; Produção cultural; Linguagem; Relações de gênero; Dramaturgia; Modernidade; Modernismo; São Paulo.

\section{Abstract}

\section{Cities, culture and gender}

Focusing on the empirical connections and on the analytical interrelations between cultural production, cities and gender, the article intends to achieve a triple purpose: to map some theoretical models being used in the analysis and in the interpretation of those realities; to argue about a specific bibliography concerning the cities, the artistic language and the social experience; to analyze the intertwining of such dimensions in the city of São Paulo, from 1940 to 1960 , mainly through the dramatists in a comparative approach with Florence, Paris and Buenos Aires. Viewing the cities as cultural arenas, as "the place of birth, of experiments and of cultural struggle" (Morse), the article shares the idea that "the cities and their representations are entangled" (Gorelik) and upholds the argument that specific cultural manifestations happen 
in specific cities according to social conditions, to the potential resources and to the constraints involving the creation, the authorship, the language and the gender relations.

Keywords: City; Cultural production; Language; Gender relations; Drama; Modernity; Modernism; São Paulo.

Texto enviado em 23/7/2015 e aprovado em 11/11/2015. DoI: 10.11606/0103-2070. ts.2016.105994.

Heloisa Pontes é professora titular do Departamento de Antropologia da Unicamp e bolsista de produtividade em pesquisa do CNPq. É autora de Intérpretes da metrópole (2010, prêmio Anpocs "melhor obra científica" atribuído em 2011), Destinos mistos (1998, prêmio Anpocs/cNpq de melhor obra científica concedido em 2000), Antropologias, histórias, experiências (organizado em conjunto com Fernanda Peixoto e Lilia Schwarcz, 2004) e Cultura e sociedade: Brasil e Argentina (organizado em conjunto com Sergio Miceli, 2014), e de diversos artigos publicados em livros e revistas científicas. Suas pesquisas estão voltadas para a sociologia e a etnografia da vida intelectual, a história social do teatro brasileiro e as relações entre gênero e corporalidade. E-mail: helopontes@uol.com.br. 